\title{
Social Support Associated with Quality of Life in Home Care Patients with Intractable Neurological Disease in Japan
}

\author{
Tomoko Nishida, ${ }^{1}$ Eriko Ando, ${ }^{2}$ and Hisataka Sakakibara ${ }^{3}$ \\ ${ }^{1}$ Department of Nursing, Sugiyama Jogakuen University, 17-3 Hoshigaoka-Motomachi, Chikusa-Ku, Nagoya 464-8662, Japan \\ ${ }^{2}$ Division of Health, Bureau of Health and Welfare, 1-1 Sannomaru 3-Chome, Naka-Ku, Nagoya 460-8508, Japan \\ ${ }^{3}$ Department of Nursing, Nagoya University Graduate School of Medicine, 1-1-20 Daiko-Minami, Higashi-Ku, \\ Nagoya 461-8673, Japan \\ Correspondence should be addressed to Tomoko Nishida, t-nishida@sugiyama-u.ac.jp
}

Received 22 June 2012; Revised 12 August 2012; Accepted 26 August 2012

Academic Editor: Linda Moneyham

Copyright ( $\odot 2012$ Tomoko Nishida et al. This is an open access article distributed under the Creative Commons Attribution License, which permits unrestricted use, distribution, and reproduction in any medium, provided the original work is properly cited.

\begin{abstract}
The aim of the present study was to investigate what kinds of social supports contribute to the higher quality of life (QOL) of home care patients with intractable neurological disease. We investigated the World Health Organization Quality of Life-BREF (WHOQOL-BREF) and social supports to 74 patients with intractable neurological disease in a city of the Aichi prefecture, Japan. Association between WHOQOL and social supports was examined using multiple logistic regression analyses adjusting activities of daily living (ADL). High WHOQOL scores were associated with "attending patient gatherings held by the public health center," "having someone who will listen empathically to anxieties or troubles," and ADL. Physical health was associated with ADL, while psychological well-being was related to "having a hobby," "having someone who will listen," and "having a hospital for admission in emergencies." Patients not having someone who will listen were more likely to participate in the gatherings. The present findings suggest that having someone who will provide emotional support is important for home care patients with neurological diseases. Patient gatherings held by the public health center were expected to provide patients with emotional support.
\end{abstract}

\section{Introduction}

Some chronic progressive degenerative neurological diseases without a cure are called "intractable neurological diseases" in Japan, where patients are provided with welfare services such as support for patient's care and subsidization. The diseases include Parkinson's disease, spinocerebellar degeneration, multiple sclerosis, and amyotrophic lateral sclerosis (ALS). They develop degenerative changes and progressively lead to motor paralysis, sensory impairment, involuntary movement, and muscle weakness/atrophy and increasing levels of physical disability [1]. Thereby the patients suffer not only medical and economical problems but also psychological difficulties. It is shown that the diseases have a significant impact on psychological well-being and quality of life (QOL) of patients as well as their physical well-being [26].

Many studies have investigated the factors affecting the QOL of patients with intractable neurological disease
[7-10]. Social support was one of the effective factors for QOL and well-being of the patients. A strong positive correlation was found between social support and QOL among patients with MS [11]. Social support had an association with lower depression in patients with Parkinson's disease [12]. On the other hand, some studies reported that negative or unsatisfied social support could produce higher psychological distress $[13,14]$. It is, hence, important to examine which social supports are helpful for patients with intractable neurological disease.

Social support is composed of material support, informational support, emotional support, and so forth. Especially emotional support is very important. Sympathy, comfort, and affection from a familiar person may be as necessary as useful information and actual help. The patients receive various supports to live at home from their family, friends, medical professionals, and volunteers. In Japan, public health departments also provide patients with support services, such as information about medical care and welfare, giving 
advice about the troubles of patients and their family and making an occasion to have contacts with patients. The aim of the present study was to investigate what kinds of social supports contribute to the QOL of home care patients with intractable neurological disease. We investigated the concrete social support by familiar persons, professionals, and public institutions to find some supportive measures to improve the QOL of home-care patients.

\section{Methods}

2.1. Subjects and Survey Methods. The present subjects were recruited from home care patients with neuromuscular diseases living in an area of A city in Japan who were entitled to receive public welfare services for the specified thirteen intractable neurodegenerative and neuromuscular diseases in 2005: Parkinson's disease, spinocerebellar degeneration, ALS, multiple sclerosis, multiple system atrophy, myasthenia gravis, Huntington's disease, adrenoleukodystrophy, subacute sclerosing panencephalitis, neurofibromatosis type 1 and 2, prion disease, amyloidosis, and moyamoya disease. The patients who had been in the hospital, had mental deficiency, and were underage were excluded from the study. This left 120 patients eligible of the subjects as in the present study.

Requests for participation in this survey were first sent by post to these 120 people together with certificates of informed consent. Eighty-nine people (74\%) returned the certificates of consent for participation, and then an anonymous self-completed questionnaire form was delivered to them and collected by post. There were surveys that were not answered completely. We excluded these from the analysis. Seventy-four people (62\%) completed questionnaires, which were used for analysis in this survey. The survey period was from November 2005 until June 2006. This study was approved by the Ethics Committee of Nagoya University School of Medicine.

2.2. Survey Contents. The Japanese version of the WHOQOL-BREF was used for QOL measurements of the home patients with intractable neurological diseases. The WHOQOL-BREF is widely used in many countries to assess the QOL of both healthy people and those with some disease, and its reliability and validity have been demonstrated [15]. The Japanese version of the WHOQOL-BREF is a 26-item, self-administered questionnaire developed by Tazaki and Nakane [16]. The WHOQOL-BREF consists of two general questions (on assessment of living quality and satisfaction with health) and four domains: physical health (7 items), psychological well-being (6 items), social relationships (3 items), and environment ( 8 items). Responses to all the items are made on a scale of 1 to 5 . In the tallying process, three items of the 26 questions are negative questions, and so the response scale is reversed for tallying. Then, the total scores of WHOQOL-BREF and each domain are transformed into a 4-to-20. The higher scores indicate a higher perceived QOL.
Six items were evaluated for activities of daily living (ADL): walking, eating, toileting, changing clothes, bathing, and going out. Each item was evaluated on a 4-point scale: "Can do myself," "Can do with a little difficulty," "Need partial assistance," and "Need complete assistance." According to the responses, the subjects were classified into three groups. People who responded "Can do myself" or "Can do with a little difficulty" to all 6 items were classified in an independent group. People who did not respond "Need complete assistance" to any question but responded "Need partial assistance" to at least 1 item were classified in a lowlevel care group, and those who responded "Need complete assistance" to at least 1 item were classified in a high-level care group.

In addition to the above, the survey included questions on the disease name under treatment, medical consultation status, frequency of talking with others, frequency of going out, having/not having a hobby, and social supports. Social supports consisted of four dimensions: personal support (having/not having a caregiver, having/not having a person who will listen empathically to anxieties or troubles, and having/not having someone who helps you whenever you are in trouble), community support (join/does not join self-help patient groups and attend/does not attend patient gatherings held by the public health center), medical support (uses/does not use home-visit nursing or rehabilitation service, has/does not have a hospital which will admit you when your condition suddenly changes, and has received/has not received consultations with medical professionals, an easy-to-understand explanation about their diseases, and upto-date information during medical visits).

2.3. Statistical Analysis. The subjects were divided into a high-score group and low-score group based on the median value of the total WHOQOL-BREF score and four domain scores. Survey items associations with the QOL were examined using multiple logistic regression analyses in which QOL score (high versus low) was the dependent variable. First, each survey item was included in the logistic regression analyses adjusting for sex, age, and ADL. Second, survey items that tended to be related $(P<0.10)$ were included in the logistic regression analyses, adjusting for sex, age, and ADL. Same analyses were conducted with each of the total WHOQOL and the 4 domains (physical health, psychological well-being, social relationships, and environment). A chi-square test was used to analyze the relation between survey items and the factors related to QOL in multiple logistic regression analysis. $P$ values of $<$ 0.05 were considered statistically significant. These statistical analyses were completed with the statistical software package SPSS 14.0J for Windows.

\section{Results}

The characteristics of the 74 people in this survey are shown in Table 1. There were 38 males (51.4\%) and 36 females $(48.6 \%)$, with ages of $22-80$ years and a mean age of $63.9 \pm$ 12.0 (mean \pm standard deviation, SD) years. The number of 
TABLE 1: Characteristics of patients with intractable neurological diseases $(N=74)$.

\begin{tabular}{|c|c|}
\hline Age & $63.9 \pm 12.0$ \\
\hline \multicolumn{2}{|l|}{ Sex } \\
\hline Male & $38(51.4)$ \\
\hline Female & $36(48.6)$ \\
\hline \multicolumn{2}{|l|}{ Disease name } \\
\hline Parkinson's disease & $42(56.8)$ \\
\hline Amyotrophic lateral sclerosis & $3(4.1)$ \\
\hline Spinocerebellar & $10(13.5)$ \\
\hline Multiple sclerosis & $7(9.5)$ \\
\hline Multiple system atrophy & $4(5.4)$ \\
\hline Myasthenia gravis & $3(4.1)$ \\
\hline Other & $5(6.8)$ \\
\hline Age at disease onset & $55.9 \pm 13.6$ \\
\hline Duration of illness (years) & $7.95 \pm 5.49$ \\
\hline \multicolumn{2}{|l|}{ Living status } \\
\hline Alone & $6(8.1)$ \\
\hline With family & $68(91.9)$ \\
\hline \multicolumn{2}{|l|}{ Caregiver } \\
\hline Family members & $45(60.8)$ \\
\hline Home care workers & $7(9.5)$ \\
\hline Not having caregiver & $22(29.7)$ \\
\hline \multicolumn{2}{|l|}{$\mathrm{ADL}$} \\
\hline Independent group & $37(50.0)$ \\
\hline Low-level care group & $15(20.3)$ \\
\hline High-level care group & $22(29.7)$ \\
\hline \multicolumn{2}{|l|}{ WHOQOL-BREF } \\
\hline Total WHOQOL score & $11.6 \pm 2.4$ \\
\hline Physical health (domain 1) & $11.2 \pm 3.2$ \\
\hline Psychological well-being (domain 2) & $11.5 \pm 3.3$ \\
\hline Social relationships (domain 3 ) & $12.0 \pm 3.2$ \\
\hline Environment (domain 4) & $12.0 \pm 2.3$ \\
\hline
\end{tabular}

Data are expressed as frequency (\%) and mean \pm standard deviation (SD).

years under medical treatment was $0-28$, with a mean of 8.0 \pm 5.5 years. Patients with Parkinson's disease accounted for more than half of the subjects (42 patients, 56.8\%), followed by 10 patients $(13.5 \%)$ with spinocerebellar degeneration, and 7 patients $(9.5 \%)$ with multiple sclerosis. In terms of ADL, 37 of the patients $(50.0 \%)$ were in the independent group, $15(20.3 \%)$ were in the low-level care group, and 22 $(29.7 \%)$ were in the high-level care group.

The Cronbach reliability coefficient for all questions on the WHOQOL-BREF was 0.93 . The coefficients for each of its domains were physical health (domain 1) 0.83, psychological well-being (domain 2) 0.89, social relationships (domain 3) 0.74 , and environment (domain 4) 0.80 . These confirm the good internal consistency of the instrument. The mean of the total WHOQOL-BREF score was $11.6 \pm 2.4$; the physical health (domain 1) score was $11.2 \pm 3.2$; psychological wellbeing (domain 2) score was $11.5 \pm 3.3$; social relationships (domain 3 ) score was $12.0 \pm 3.2$; environment (domain 4 ) score was $12.0 \pm 2.3$.
Based on the median value of 11.6 in the total WHOQOL-BREF score, the subjects were divided into a high-score group $(n=35)$ and a low-score group $(n=$ 39). Logistic regression analyses adjusting for age, sex, and ADL (Table 2) showed significant differences between the two groups in ADL (odds ratio (OR) 2.19, 95\% confidence interval (CI) 1.19-4.01), having a hobby (OR 3.17, 95\% CI 1.30-10.64), having a person who will listen empathically to anxieties or troubles (OR 3.29, 95\% CI 1.02-10.62), and attending patient gatherings held by the public health center (OR 3.83, 95\% CI 1.19-12.34). The high QOL score was associated with frequency of going out (OR 1.98, 95\% CI 0.97-4.05), though not statistically significant. To clarify factors closely related to QOL score, a multiple logistic regression analysis was conducted with regards to all these factors. As shown in Table 3, significant associations were encountered between the high QOL score and attending gatherings held by the public health center (OR 6.07, 95\% CI 1.37-26.88) and having someone who will listen empathically to anxieties or troubles (OR 6.38, 95\% CI 1.31-30.99), in addition to ADL (OR 2.17, 95\% CI 1.06-4.43).

Similarly, multiple logistic regression analyses were conducted after adjusting for age, sex, and ADL for each of the 4 domains (Table 4). High physical health (domain 1) was associated with ADL (OR 2.57, 95\% CI 1.27-5.20) and having a person who will listen empathically to anxieties or troubles (OR 3.42, 95\% CI 0.98-11.92). High psychological well-being (domain 2) was associated with having a hobby (OR 5.78, 95\% CI 1.31-25.52), having a person who will listen empathically to anxieties or troubles (OR 8.79, 95\% CI 1.17-65.93), having a hospital for admission (OR 7.66, 95\% CI 1.16-50.36), and attending patient gatherings held by the public health center (OR 5.00, 95\% CI 0.95-26.32). High social relationships (domain 3) were associated with not using home-visit nursing or rehabilitation service (OR $0.04,95 \%$ CI $0.01-0.30$ ) and having a person who will listen empathically to anxieties or troubles (OR 4.17, 95\% CI 1.0416.64). High environment (domain 4) was associated with having a hospital for admission (OR 5.57, 95\% CI 1.29-24.00) and having a hobby (OR 3.64, 95\% CI 1.10-12.08).

The present study showed an association between the total QOL score and the items of "having someone who will listen empathically to anxieties and troubles" and "attending patient gatherings held by the public health center." The characteristics of the factor were further investigated in Table 5. People having someone who will listen empathically to anxieties and troubles were also more likely to have someone who would help them $(P<0.001)$. In their relations with medical institutions, they tended to understand the explanations given by their doctors about their disease $(P=$ $0.054)$ and to receive up-to-date information during medical visits $(P=0.086)$. They also tended to enjoy a hobby $(P=$ $0.070)$. On the other hand, people not having someone who will listen tended to join self-help patient groups $(P=0.056)$ and attending patient gatherings held by the public health center $(P=0.058)$. There was no difference in living with family or not and the severity of ADL. Thirty-five replied "spouse" about the person who will listen empathically to anxieties or troubles, and 17 replied "other member 
TABLE 2: Factors related to the total WHOQOL score (Low-score and high-score groups).

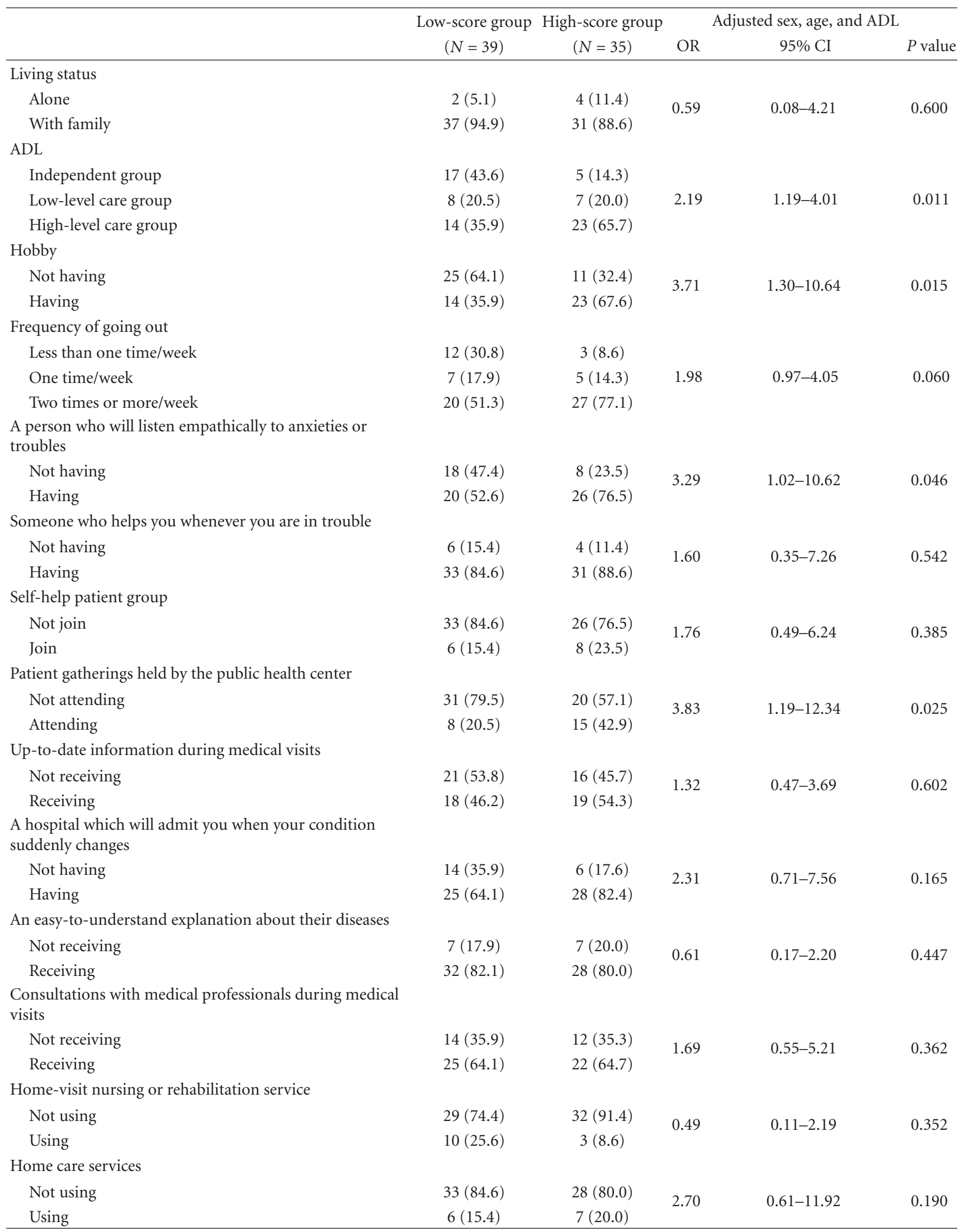

Data are expressed as frequency (\%), odds ratio (OR), and 95\% confidential interval (CI) of logistic regression analysis.

Odds ratio shows relation with the total QOL score (low-score and high-score groups) and each factor after adjusting for sex, age, and ADL, using multiple logistic regression analysis.

$P$ value by multiple logistic regression analysis. 
TABLE 3: Correlates of the total WHOQOL score (low- and high-score groups).

\begin{tabular}{|c|c|c|c|}
\hline & \multicolumn{3}{|c|}{ Multiple adjustment } \\
\hline & OR & $95 \% \mathrm{CI}$ & $P$ value \\
\hline $\mathrm{ADL}$ & 2.17 & $1.06-4.43$ & 0.033 \\
\hline Hobby & 2.25 & $0.69-7.37$ & 0.179 \\
\hline Frequency of going out & 1.78 & $0.81-3.94$ & 0.152 \\
\hline A person who will listen empathically to anxieties or troubles & 6.38 & $1.31-30.99$ & 0.022 \\
\hline Patient gatherings held by public health center & 6.07 & $1.37-26.88$ & 0.018 \\
\hline
\end{tabular}

Data are expressed by involving odds ratio (OR) and 95\% confidential interval (CI) of logistic regression analysis.

Odds ratio shows value turned on sex, age, ADL, a person who will listen empathically to anxieties or trouble, frequency of going out, not attending/attending patient gatherings held by the public health center, and not having/having hobby.

$P$ value by multiple logistic regression analysis.

TABLE 4: Correlates of each domain of WHOQOL-BREF score (low- and high-score groups).

\begin{tabular}{|c|c|c|c|c|}
\hline & \multicolumn{2}{|c|}{ Adjusted sex, age, and ADL } & \multicolumn{2}{|c|}{ Multiple adjustment } \\
\hline & $\mathrm{OR}^{\mathrm{a}}(95 \% \mathrm{CI})$ & $P$ value & $\mathrm{OR}^{\mathrm{b}}(95 \% \mathrm{CI})$ & $P$ value \\
\hline \multicolumn{5}{|l|}{ Physical health (domain 1) } \\
\hline $\mathrm{ADL}$ & & & $2.57(1.27-5.20)$ & 0.009 \\
\hline A person who will listen empathically to anxieties or troubles & & & $3.42(0.98-11.92)$ & 0.053 \\
\hline \multicolumn{5}{|l|}{ Psychological well-being (domain 2) } \\
\hline $\mathrm{ADL}$ & - & - & $1.60(0.72-3.59)$ & 0.249 \\
\hline Hobby & $8.47(2.44-29.47)$ & 0.001 & $5.78(1.31-25.52)$ & 0.021 \\
\hline A person who will listen empathically to anxieties or troubles & $3.42(0.98-11.90)$ & 0.054 & $8.79(1.17-65.93)$ & 0.034 \\
\hline A hospital which will admit you when your condition suddenly changes & $3.34(0.92-12.08)$ & 0.066 & $7.66(1.16-50.36)$ & 0.034 \\
\hline Frequency of going out & $2.10(0.98-4.50)$ & 0.057 & $1.87(0.72-4.86)$ & 0.196 \\
\hline Patient gatherings held by the public health center & $3.18(1.01-9.98)$ & 0.048 & $5.00(0.95-26.32)$ & 0.058 \\
\hline \multicolumn{5}{|l|}{ Social relationships (domain 3 ) } \\
\hline $\mathrm{ADL}$ & - & - & $0.57(0.24-1.39)$ & 0.219 \\
\hline A person who will listen empathically to anxieties or troubles & $4.76(1.57-14.37)$ & 0.006 & $4.17(1.04-16.64)$ & 0.043 \\
\hline Someone who helps you whenever you are in trouble & $5.27(1.17-23.81)$ & 0.031 & $3.15(0.53-18.72)$ & 0.208 \\
\hline Home-visit nursing or rehabilitation service & $0.04(0.01-0.27)$ & 0.001 & $0.04(0.01-0.30)$ & 0.001 \\
\hline \multicolumn{5}{|l|}{ Environment (domain 4) } \\
\hline $\mathrm{ADL}$ & - & - & $0.53(0.26-1.08)$ & 0.082 \\
\hline A hospital which will admit you when your condition suddenly changes & $4.49(1.36-14.76)$ & 0.013 & $5.57(1.29-24.00)$ & 0.021 \\
\hline Up-to-date information during medical visits & $2.31(0.86-6.19)$ & 0.097 & $2.62(0.75-9.11)$ & 0.131 \\
\hline Hobby & $2.46(0.93-6.53)$ & 0.070 & $3.64(1.10-12.08)$ & 0.035 \\
\hline Self-help patient group & $3.07(0.84-11.20)$ & 0.089 & $4.07(0.88-18.93)$ & 0.073 \\
\hline
\end{tabular}

Data are expressed as odds ratio (OR) and 95\% confidential interval (CI) of logistic regression analysis.

${ }^{a}$ Odds ratio shows relation with each domain of WHOQOL-BREF and each factor after adjusting for sex, age, and ADL.

${ }^{b}$ Odds ratio shows relation with each domain and the factors that tend to be related $(P<0.10)$ when adjusting for sex, age, and ADL.

$P$ value by multiple logistic regression analysis.

of their family" (including multiple answers). Nine replied "friends or other person." Patients who had attended patient gatherings held by the public health center also tended to join self-help patient groups $(P=0.004)$. There were no differences in other items.

\section{Discussion}

The present study showed that the total WHOQOL of home care patients with intractable neurological disease was associated with "attending patient gatherings held by the public health center" and "having someone who will listen empathically to anxieties or troubles" as well as ADL. ADL was associated with physical health, while "having someone who will listen" was related with psychological well-being. Earlier studies have shown an association between QOL of patients with neurological diseases and the severity of ADL $[4,17]$. Although the present study showed a similar relation between the total WHOQOL score and ADL, the relationship with ADL was found in the physical domain, but not in the psychological domain. The present findings may suggest that emotional support such as "having someone who will listen empathically to anxieties or troubles" is important for home care patients with intractable neurological diseases, regardless of the severity of ADL. 
TABLE 5: Relation with a person who will listen empathically to anxieties or troubles with the use of welfare resources and medical institutions.

\begin{tabular}{|c|c|c|c|c|c|}
\hline & \multicolumn{2}{|c|}{$\begin{array}{l}\text { Have no person } \\
\text { who will listen }\end{array}$} & \multicolumn{2}{|c|}{$\begin{array}{l}\text { Have person } \\
\text { who will listen }\end{array}$} & \multirow[t]{2}{*}{$P$ value } \\
\hline & $n$ & $\%$ & $n$ & $\%$ & \\
\hline \multicolumn{6}{|l|}{ Living status } \\
\hline Alone & 1 & 3.8 & 5 & 10.9 & \multirow{2}{*}{0.408} \\
\hline With family & 25 & 96.2 & 41 & 89.1 & \\
\hline \multicolumn{6}{|l|}{ Hobby } \\
\hline Not having & 17 & 65.4 & 18 & 40.0 & \multirow{2}{*}{0.070} \\
\hline Having & 9 & 34.6 & 27 & 60.0 & \\
\hline \multicolumn{6}{|c|}{ Patient gatherings held by the public health center } \\
\hline Not attending & 14 & 53.8 & 36 & 78.3 & \multirow{2}{*}{0.058} \\
\hline Attending & 12 & 46.2 & 10 & 21.7 & \\
\hline \multicolumn{6}{|c|}{ Someone who helps you whenever you are in trouble } \\
\hline Not having & 9 & 34.6 & 1 & 2.2 & \multirow{2}{*}{$<0.001$} \\
\hline Having & 17 & 65.4 & 45 & 97.8 & \\
\hline \multicolumn{6}{|c|}{ Self-help patient group } \\
\hline Not join & 18 & 69.2 & 40 & 88.9 & \multirow{2}{*}{0.056} \\
\hline Join & 8 & 30.8 & 5 & 11.1 & \\
\hline \multicolumn{6}{|c|}{ Up-to-date information during medical visits } \\
\hline Not receiving & 17 & 65.4 & 19 & 41.3 & \multirow{2}{*}{0.086} \\
\hline Receiving & 9 & 34.6 & 27 & 58.7 & \\
\hline \multicolumn{6}{|c|}{ An easy-to-understand explanation about their diseases } \\
\hline Not receiving & 8 & 30.8 & 5 & 10.9 & \multirow{2}{*}{0.054} \\
\hline Receiving & 18 & 69.2 & 41 & 89.1 & \\
\hline \multicolumn{6}{|c|}{ Consultations with medical professionals during medical visits } \\
\hline Not receiving & 13 & 50.0 & 13 & 28.3 & \multirow{2}{*}{0.112} \\
\hline Receiving & 13 & 50.0 & 33 & 71.7 & \\
\hline
\end{tabular}

Data are expressed as frequency (\%). $P$ value by chi-square test.

Previous studies have reported that QOL was linked with depression, fatigue, and anxiety among patients with neurological diseases $[5,18,19]$. A study has indicated that depression was a major contributor to the QOL scores of patients with Parkinson's disease [6]. Meanwhile, an association between QOL and the existence of confiding and emotional support has been reported among people with neuromuscular disorders [20], Parkinson's disease [14], and ALS patients [21]. It is, hence, considered that emotional supports from family, friends, and health professionals are important to improve their symptoms of depression and QOL $[9,22]$. In the present study, people having someone who will listen were also more likely to have someone who helps whenever he or she is in trouble. These findings suggested that the presence of someone nearby who will provide emotional as well as physical support was a key factor in the QOL of patients with neurological diseases.

Most of the patients replied "spouse" or "other member of their family" about persons who will listen empathically to anxieties or troubles. A family member is one of the most important factors affecting the QOL of patients with neurological disease [23]. A previous study of ALS patients showed the importance of the presence of caring family as well as the availability of technical aids [24]. In the present study, most patients (91.9\%) had lived with family, and $60.8 \%$ had been cared for by family members. However, about one-third (35.1\%) of the present patients replied "no" to a question of "having someone who will listen empathically to anxieties or troubles." These results may suggest that their family cannot necessarily be such an emotional supporter as a person who would listen empathically to anxieties of the patients, even if patients live with family. On the other hand, family caregivers may bear physical and psychological distress [25-27]. A study on family caregivers of patients with Parkinson's disease has reported an association between the caregiver's psychological burden and QOL of the patients [28]. We could not elucidate the psychological states and burden of their family, because we did not investigate their family. But family caregivers may have anxieties or troubles due to the burden of caring, and they would also need social supports.

The present results showed a close relationship between the total QOL score and "attending patient gatherings held by the public health center." Such relations were encountered in the psychological domain, though the significance was borderline $(P=0.058)$. The public health center in the city under study holds gatherings regularly for patients 
with neurological diseases and their family to contact and communicate with each other. On these occasions, public health nurses counsel the patients and their families. Such gatherings may be good occasions to provide patients and their family with emotional support to improve their QOL. Reversely, it was also shown that some patients not having someone who will listen were more likely to participate in the gatherings. The patients and families may attend such gatherings to seek out someone who will listen empathically to them or where they can find companionship for physical and emotional help.

In the present study, "having a hospital which will admit you when your condition suddenly changes" was associated with QOL in the psychological domain and environment domain. Previous studies have reported that anxiety about a medical institute to be accepted in emergencies was associated with QOL [29] and that patients satisfied with their medical care tended to have higher QOL $[2,29]$. A study of ALS patients reported that higher patient satisfaction was related to their feeling that the physician understood their feelings [30]. For home care patients with intractable neurological diseases, having a certain hospital for admission can provide a sense of ease, as a place that can deal with sudden changes or emergencies. Medical institutions and professionals are necessary for patients as a place of refuge and people who can give medical care and provide emotional supports.

There were some limitations in this study. The present study had only 74 (62\%) subjects within a limited area. These results may not adequately reflect the general conditions of home care patients with neurological diseases in Japan. Second, neurological diseases of participants in this study were of several kinds, so the findings may have been potentially affected by the kind of neurological diseases. Moreover, their QOL was assessed using the WHOQOLBREF, a general QOL assessment, though it is used to assess the QOL of people with some disease as well. Specific assessment items may be required in the case of individual neurological diseases. Finally, this was a cross-sectional study, but longitudinal assessments will also be warranted since neurological diseases gradually lead to deterioration.

\section{Conclusion}

The present study found that the QOL of home care patients with intractable neurological disease was associated with "attending patient gatherings held by the public health center" and "having someone who will listen empathically to anxieties or troubles" as well as ADL. The present findings suggested that having someone who will provide emotional support was important for home care patients with neurological diseases. Furthermore, patient gatherings held by the public health center were expected to provide patients with emotional support. The patients and their families may attend such gatherings to seek out someone who will listen empathically to them or where they can find companionship for physical and emotional help. Public health nurses may be able to use the gatherings to provide emotional support to patients.

\section{Conflict of Interests}

There are no conflict of interests to disclose.

\section{References}

[1] D. L. Kasper, E. Braunwald, S. Hauser et al., Harrison's Principles of Internal Medicine, McGraw-Hill, New York, NY, USA, 16th edition, 2004.

[2] Global Parkinson's Disease Survey Steering Committee, "Factors impacting on quality of life in Parkinson's disease: results from an international survey," Movement Disorders, vol. 17, no. 1, pp. 60-67, 2002.

[3] M. S. Hirayama, S. Gobbi, L. T. B. Gobbi, and F. Stella, "Quality of life (QoL) in relation to disease severity in Brazilian Parkinson's patients as measured using the WHOQOL-BREF," Archives of Gerontology and Geriatrics, vol. 46, no. 2, pp. 147160, 2008.

[4] K. H. Karlsen, E. Tandberg, D. Årsland, and J. P. Larsen, "Health related quality of life in Parkinson's disease: a prospective longitudinal study," Journal of Neurology Neurosurgery and Psychiatry, vol. 69, no. 5, pp. 584-589, 2000.

[5] A. Schrag, F. Geser, M. StampferKountchev et al., "Healthrelated quality of life in multiple system atrophy," Movement Disorders, vol. 21, no. 6, pp. 809-815, 2006.

[6] J. Sławek, M. Derejko, and P. Lass, "Factors affecting the quality of life of patients with idiopathic Parkinson's diseasea cross-sectional study in an outpatient clinic attendees," Parkinsonism and Related Disorders, vol. 11, no. 7, pp. 465468, 2005.

[7] M. B. Bromberg, "Assessing quality of life in ALS," Journal of Clinical Neuromuscular Disease, vol. 9, no. 2, pp. 318-325, 2007.

[8] L. Dennison, R. Moss-Morris, and T. Chalder, "A review of psychological correlates of adjustment in patients with multiple sclerosis," Clinical Psychology Review, vol. 29, no. 2, pp. 141-153, 2009.

[9] K. S. Malcomson, L. Dunwoody, and A. S. Lowe-Strong, "Psychosocial interventions in people with multiple sclerosis: a review," Journal of Neurology, vol. 254, no. 1, pp. 1-13, 2007.

[10] J. Marinus, C. Ramaker, J. J. van Hilten, and A. M. Stiggelbout, "Health related quality of life in Parkinson's disease: a systematic review of disease specific instruments," Journal of Neurology Neurosurgery and Psychiatry, vol. 72, no. 2, pp. 241248, 2002.

[11] C. Schwartz and R. Frohner, "Contribution of demographic, medical, and social support variables in predicting the mental health dimension of quality of life among people with multiple sclerosis," Health and Social Work, vol. 30, no. 3, pp. 203-212, 2005.

[12] Y. Cheng, C. Liu, C. Mao, J. Qian, K. Liu, and G. Ke, "Social support plays a role in depression in Parkinson's disease: a cross-section study in a Chinese cohort," Parkinsonism and Related Disorders, vol. 14, no. 1, pp. 43-45, 2008.

[13] L. H. Goldstein, L. Atkins, S. Landau, R. G. Brown, and P. N. Leigh, "Longitudinal predictors of psychological distress and self-esteem in people with ALS," Neurology, vol. 67, no. 9, pp. 1652-1658, 2006.

[14] J. Simpson, K. Haines, G. Lekwuwa, J. Wardle, and T. Crawford, "Social support and psychological outcome in people with Parkinson's disease: evidence for a specific pattern of associations," British Journal of Clinical Psychology, vol. 45, no. 4, pp. 585-590, 2006. 
[15] The WHOQOL Group, "Development of the World Health Organization WHOQOL-BREF quality of life assessment," Psychological Medicine, vol. 28, no. 3, pp. 551-558, 1998.

[16] M. Tazaki and M. Nakane, WHOQOL26 Guidance, KanekoShobo, Tokyo, Japan, 1997.

[17] T. Iizuka, Y. Ogata, M. Minowa, and T. Fujita, "A follow-up study on effects of ADL deterioration on QOL in patients with neurological intractable diseases," Nippon Kōshū Eisei Zasshi, vol. 46, no. 8, pp. 595-603, 1999.

[18] V. Janardhan and R. Bakshi, "Quality of life in patients with multiple sclerosis: the impact of fatigue and depression," Journal of the Neurological Sciences, vol. 205, no. 1, pp. 51-58, 2002.

[19] A. Vignola, A. Guzzo, A. Calvo et al., "Anxiety undermines quality of life in ALS patients and caregivers," European Journal of Neurology, vol. 15, no. 11, pp. 1231-1236, 2008.

[20] L. H. Goldstein, L. Atkins, and P. N. Leigh, "Correlates of quality of life in people with motor neuron disease (MND)," Amyotrophic Lateral Sclerosis and other Motor Neuron Disorders, vol. 3, no. 3, pp. 123-129, 2002.

[21] K. Okamoto, T. Kihira, T. Kondo et al., "Changing QOL in ALS patient and examination concerning the related factor," Kosei no Shihyo, vol. 52, no. 5, pp. 29-33, 2005 (Japanese).

[22] J. E. McLeod and D. M. Clarke, "A review of psychosocial aspects of motor neurone disease," Journal of the Neurological Sciences, vol. 258, no. 1-2, pp. 4-10, 2007.

[23] M. A. Lee, R. W. Walker, A. J. Hildreth, and W. M. Prentice, "Individualized assessment of quality of life in idiophatic Parkinson's disease," Movement Disorders, vol. 21, no. 11, pp. 1929-1934, 2006.

[24] M. Hecht, T. Hillemacher, E. Gräsel et al., "Subjective experience and coping in ALS," Amyotrophic Lateral Sclerosis and Other Motor Neuron Disorders, vol. 3, no. 4, pp. 225-232, 2002.

[25] A. Gauthier, A. Vignola, A. Calvo et al., "A longitudinal study on quality of life and depression in ALS patient-caregiver couples," Neurology, vol. 68, no. 12, pp. 923-926, 2007.

[26] M. Miyashita, Y. Narita, A. Sakamoto et al., "Care burden and depression in caregivers caring for patients with intractable neurological diseases at home in Japan," Journal of the Neurological Sciences, vol. 276, no. 1-2, pp. 148-152, 2009.

[27] R. A. Ray and A. F. Street, "Caregiver bodywork: family members' experiences of caring for a person with motor neurone disease," Journal of Advanced Nursing, vol. 56, no. 1, pp. 35-43, 2006.

[28] P. Martínez-Martín, J. Benito-León, F. Alonso et al., "Quality of life of caregivers in Parkinson's disease," Quality of Life Research, vol. 14, no. 2, pp. 463-472, 2005.

[29] S. Kodera, K. Tanji, A. Watanabe et al., "Intractable disease Patient's QOL and relation between medical treatment and health needs," Kosei no Shihyo, vol. 51, no. 15, pp. 1-7, 2004 (Japanese).

[30] A. Chiò, A. Montuschi, S. Cammarosano et al., "ALS patients and caregivers communication preferences and information seeking behaviour," European Journal of Neurology, vol. 15, no. 1, pp. 51-60, 2008. 


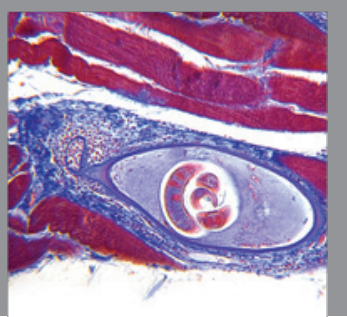

Gastroenterology

Research and Practice
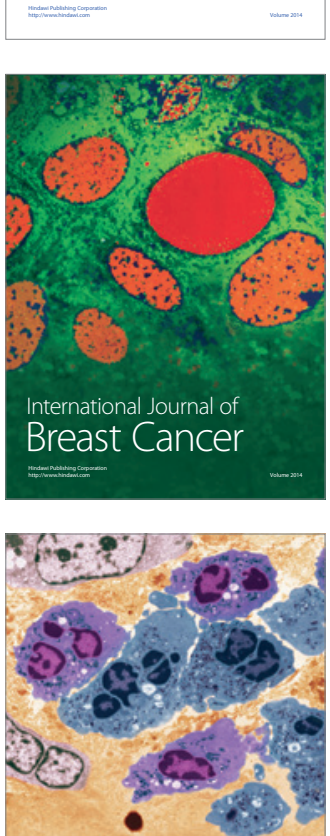

International Journal of Inflammation
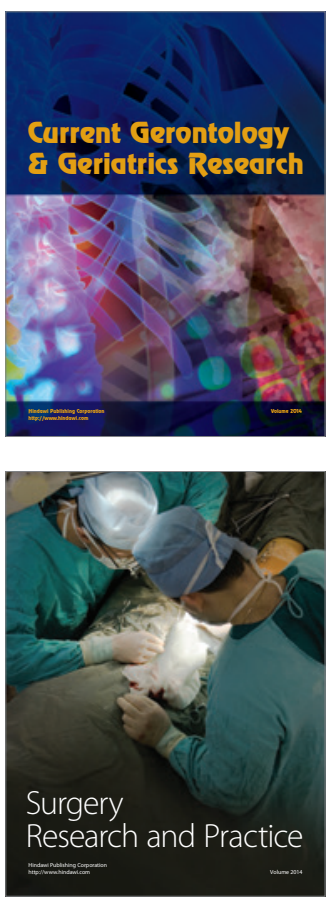
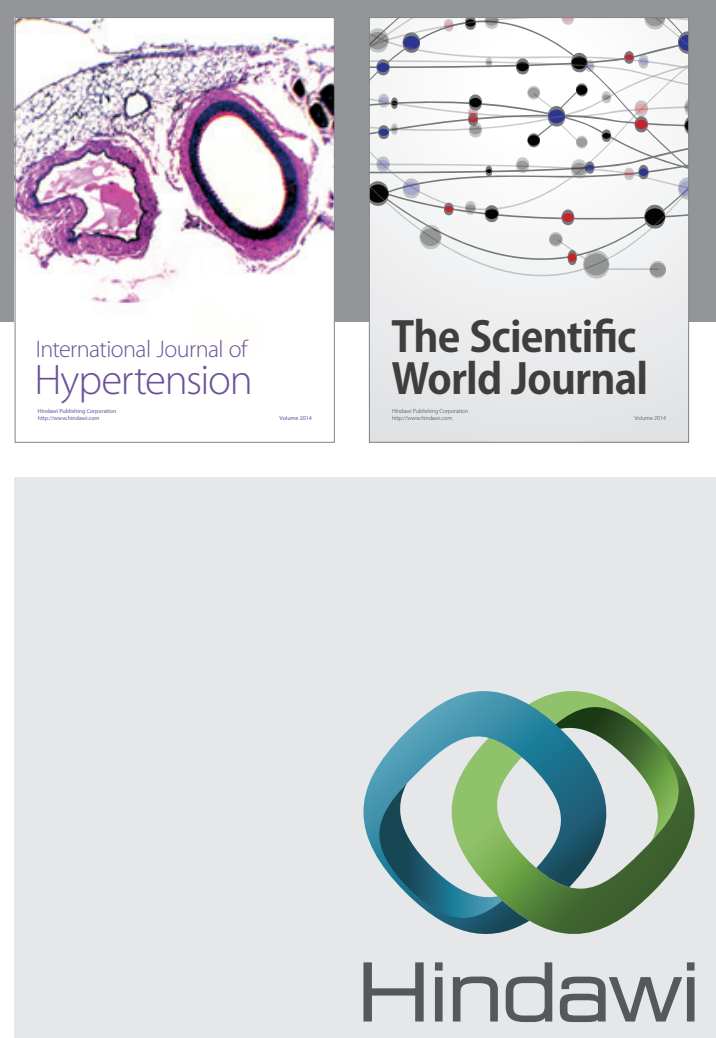

Submit your manuscripts at

http://www.hindawi.com
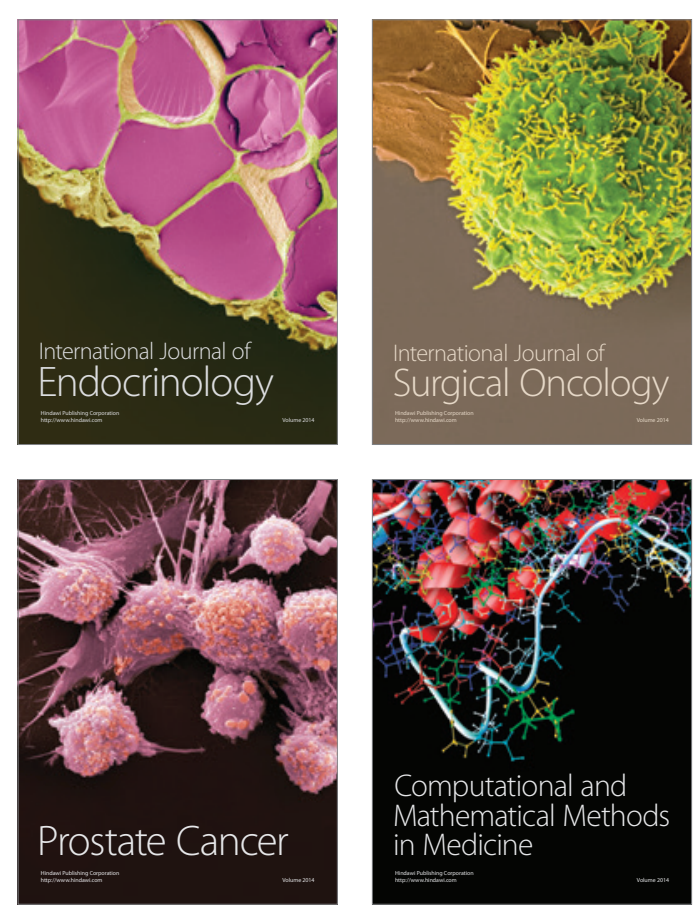
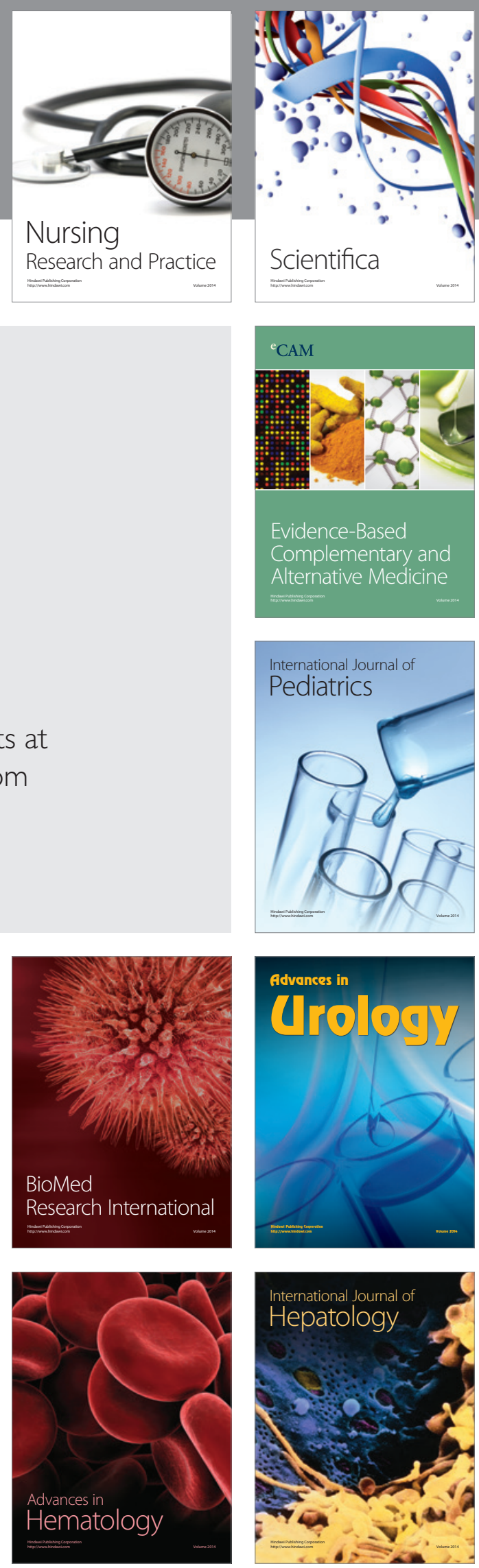